\title{
Design and Validation of an Adaptive Cubesat Transmitter System Using a Thermal Vacuum Chamber (TVAC)
}

\author{
F. D. Jaswar, T. A. Rahman, Y.A. Ahmad
}

\begin{abstract}
CubeSat in a low earth orbit primarily uses a UHF transmitter with a fixed RF output power. In this paper, the design of the CubeSat transmitter with adaptive power control ability is presented. The design drive is to optimise the SNR and overcome the variability of the propagation path length due to different ground station elevation angles by adjusting its transmitting power. The TVAC test is conducted to validate the performance of the adaptive function in the transmitter. The TVAC is used to emulate the satellite condition in an outer space environment. Four thermal cycles starting from $+60^{\circ} \mathrm{C}$ to $-20^{\circ} \mathrm{C}$ with less than 10-5Pa pressure condition are employed, which was conducted at the KIT CeNT, Japan. The transmitter was integrated inside the satellite structure as a complete CubeSat system. The output power of the transmitter is tested from $0.5 \mathrm{~W}$ to $2 W$ based on the proposed satellite adaptive mode. The frequency stability of the transmitter is monitored and complies with an average of $70 \%$ below requirement, which is less than 2ppm. The results indicate that the $R F$ output power is adjustable to operate as the proposed CubeSat adaptive transmitter in a thermal vacuum condition, which was first developed in Malaysia.
\end{abstract}

Keywords : Adaptive system, low earth orbit satellites, UHF communication, CubeSat, transmitter.

\section{INTRODUCTION}

The typical approach to maintain an affordable CubeSat mission is to use a simple communication system, which based on the ultra high frequency (UHF) link with fixed-transmit power [1]. However, CubeSat in the low earth orbit (LEO) does not have relative motion with the earth rotation, resulting in variable propagation path length that affects the transmission signal. The range or distance between a satellite and a ground station, therefore, is dependent on the elevation angle of the ground station, which is also known as the slant range. As the satellite flies above the horizon, the elevation angle increases; thus, the slant range decreases to its shortest distance (directly overhead), which is also known as the altitude of the satellite. The slant range condition of a satellite in space is inversely proportional with the ground station receiving antenna elevation angle. In LEO communication worst case scenario, the maximum distance or range which the satellite will be in view is at the minimum

Revised Manuscript Received on October 22, 2019.

* Correspondence Author

Fitri Dewi Jaswar*, Universiti Teknologi Malaysia, Skudai, Johor, Malaysia. Email: fitridewi268@gmail.com

Tharek Abd. Rahman, WCC, Universiti Teknologi Malaysia, Skudai, Johor, Malaysia. Email: tharek@utm.my

Yasser Asrul Ahmad, Kulliyah of Engineering, IIUM, Gombak, Selangor, Malaysia. Email:yasser@iium.edu.my elevation angle of $5^{\circ}$. For practical communication purposes, the minimum elevation angle is typically greater than $5^{\circ}$. The elevation angle typically ranges from $10^{\circ}$ to $90^{\circ}$ as the satellite rises above the horizon to directly above the ground station [2]. The lower receiving antenna elevation angle during satellite passes will increase the free space loss [3]. Thus, decreasing the signal-to-noise ratio (SNR) and increasing the bit-error-rate (BER). A higher satellite transmitted power is required to maintain the received SNR with the corresponding BER.

The practical approach in designing a satellite communication link is to ensure that the link margin is available at the minimum elevation angle [4]. In order to overcome the variable free space loss, the minimum receiving antenna elevation angle is used in the link budget analysis to have a fixed transmit power for all passes condition [5]. The fixed transmission technique is not an optimise solutions and create large margin condition especially when the satellite passes at high elevation angle [6]. Having a large margin in a CubeSat communication link means transmitter wastes higher power consumption, and the signal-to-noise ratio is not optimised. Transmitter with an adaptive capability to select the radio frequency (RF) transmit power and data rate is proposed to improve and optimise the transmission link.

The idea of implementing adaptive methods on CubeSat are currently research by others [7]. Utah State University project, a multi-functional solar panel antenna for CubeSat developed a single antenna structure that can perform functions of about four antennas [8]. The antenna is designed to work at about three different usable frequencies. However, other parameters of the antenna such as gain, directivity and beam width at different frequencies are not discussed. Eclipse Micropower Design's project has developed a smart power supply for CubeSat that can switch-off the satellite power systems by itself either for the necessity of use or because of fault in the system [9]. Other than that, there is also research on the adaptive receiver for CubeSat mission. An adaptive receiver that can maintain a reliable and stable gain-to-noise $(\mathrm{G} / \mathrm{T})$ ratio is developed using a reconfigurable low-noise amplifier, by research program at the University of Manchester by S. C. Ekpo [10]. The implementation of adaptive receiver enables ultrasensitive satellite receiver design for optimal, cost-effective and sustainable during satellite operations. 
The CubeSat transmitter will be subjected to different heat condition starting from the launch pad, during ascent into orbit, fairing jettisoning, and orbit insertion. Once it is in space, the transmitter will be operating in a vacuum condition. The near vacuum condition of low earth orbit has to be taken into account in designing and validating the CubeSat transmitter in ensuring it can operate in a reasonable operating temperature without convection [11]. In the vacuum of space, there is no convection, and the excess heat has to be transferred by conduction and radiating the heat. In space, the CubeSat transmitter will be subjected to the heat from the Sun, the Earth albedo thermal emission, and the cold outer space. The power system of the satellite will be generating heat. The transmitter also generates heat primarily from the power amplifier module [12]. As the satellite transit from sunlit into eclipse condition about 14 times a day, in near-equatorial orbit, the CubeSat transmitter is subjected to the sudden extreme in thermal environments [13]. The transmitter must be robust and reliable to operate in the extreme environmental conditions.

In this paper, the main highlight is the adaptive transmitter performance in the thermal vacuum condition, and this proves that the developed transmitter is suitable for CubeSat application. The typical approached in the verification process of the CubeSat transmitter is to make sure that the transmit power and frequency are stable within the required specification. However, the focus for an adaptive transmitter is during the RF transmit power reconfigurable test and at the same time performs the same specification as other CubeSat transmitters. From this paper, the transmitter heat circulation design which is including the HPA ground and aluminium casing is validated. This design has provided the ability to transmit continuously within satellite pass duration. The adaptive transmitter control unit model is introduced with a general description of the developed transmitter and compared to other adaptive solutions also explained to provide an understanding of the overall development process.

\section{METHODOLOGY}

A transmission subsystem for a CubeSat is designed with significant constraints: mass and dimensions, power system, communications link, onboard data handling system, and attitude determination and control [14][15]. The size restriction influences the communication subsystem design, especially when selecting the antenna gain or amplifier gain. Satellite system requirements, such as the distance range, frequency allocation band and standard modulation technique, are applied even though the satellite size is limited to $10 \mathrm{~cm} \times 10 \mathrm{~cm} \times 30 \mathrm{~cm}$, the mass is less than $4 \mathrm{~kg}$, and the power consumption is small compared with other nano-satellites or micro-satellites [16]. The UHF transmitter with an adaptive transmitter control unit (ATCU) model is designed to comply with these requirements [13]. Due to the space environment requirement, the transmitter needs to have the capability of maintaining its performance within a wide temperature range. This paper will discuss the transmitter design and its ability to adjust the output power in different temperature conditions using a space environment simulated by thermal vacuum conditions.

\section{A. Transmitter Design Description}

UHF transmission system guarantees the transmission of telemetry and image data from the satellite to the ground station. It consists of a baseband modulator module and a transmitter module. The baseband modulator is working at 9.6 kbps or 19.2 kbps data rate using Gaussian Frequency Shift Keying (GFSK) modulation technique [17]. The frequency range for transmission carrier is from $430 \mathrm{MHz}$ to $440 \mathrm{MHz}$. The transmitter specifications are listed in Table I.

Table I: UHF Transmitter Specification

\begin{tabular}{|l|l|}
\hline \multicolumn{1}{|c|}{ Item } & Specification \\
\hline Frequency & $430-440 \mathrm{MHz}$ (UHF band) \\
\hline $\begin{array}{l}\text { Transmit Output } \\
\text { power }\end{array}$ & 0.5 to $2 \mathrm{~W}$ \\
\hline Data rate & $9.6 \mathrm{kbps}, 38.4 \mathrm{kbps}$ \\
\hline $\begin{array}{l}\text { Phase Noise at } 10 \\
\text { kHz offset }\end{array}$ & $<-95 \mathrm{dBc} / \mathrm{Hz}$ \\
\hline Interface & UART, SMA connector \\
\hline Power Supply & $3.3 \mathrm{~V}, 5 \mathrm{~V}$ \\
\hline Current (max) & $0.6 \mathrm{~A}$ \\
\hline $\begin{array}{l}\text { Power Consumpti } \\
\text { on }\end{array}$ & $<5 \mathrm{~W}$ \\
\hline Dimension & $91 \mathrm{mmx} 96 \mathrm{~mm} \times 15 \mathrm{~mm}$ \\
\hline
\end{tabular}

The transmitter is designed with an interface to other subsystems such as antenna, Power Module and Onboard Computer (OBC) as per shown in Fig. 1. The adaptive capabilities only involve the synthesiser module where the data rate and gain of the AGC amplifier can be configured Other modules such as pre-amp and HPA are designed with a fixed configuration.

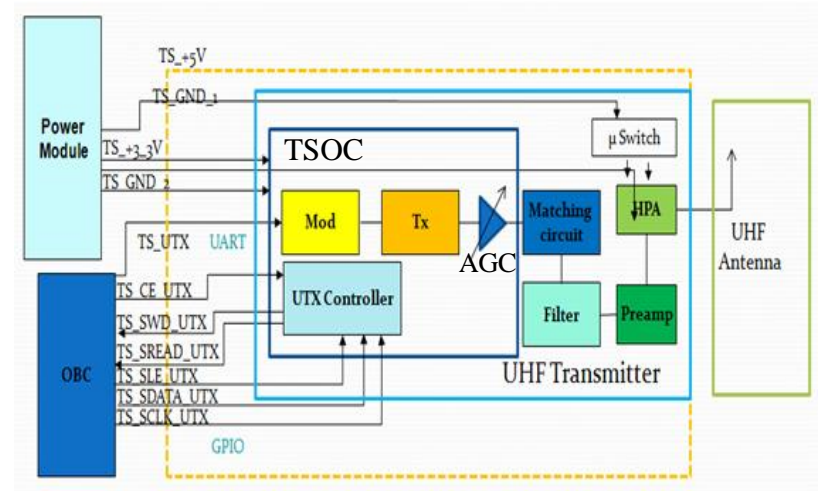

Fig. 1.Block Diagram of Transmitter Design and Interface.

The transmitter consists of Transmitter-System On-Chip (TSOC), preamp or driver amplifier and high-power amplifier (HPA). The transmitter (TSOC) output power is reconfigurable from $-16 \mathrm{dBm}$ to $+13 \mathrm{dBm}$ in 63 steps programmable inputs and has an automatic power ramp control to prevent spectral splatter. 
The preamp and HPA gain will increase the RF transmit output power to $33 \mathrm{dBm}$ as per shown in Table II.

\begin{tabular}{|c|c|c|c|c|c|}
\hline Item & $\begin{array}{c}\text { Tx } \\
\text { with } \\
\text { AGC }\end{array}$ & Preamp & $\begin{array}{c}\mathrm{HP} \\
\mathrm{A}\end{array}$ & $\begin{array}{l}\text { Coax \& } \\
\text { antenn } \\
\text { a Feed }\end{array}$ & $\begin{array}{c}\text { Antenn } \\
\text { a }\end{array}$ \\
\hline Gain (dB) & & 14 & 12 & -0.2 & 0.0 \\
\hline Output Power (W) & & 0.1 & 2.0 & 1.8 & 1.8 \\
\hline Output Power (dBm) & 7 & 21 & 33 & 32.55 & 32.55 \\
\hline $\mathrm{P} 1 \mathrm{~dB}(\mathrm{dBm})$ & 13 & 22 & $\begin{array}{c}32 . \\
5\end{array}$ & & \\
\hline
\end{tabular}

HPA Output Power : 2W @ 33dBm

Output RF Transmit Power at the antenna: 1.8W @ $32.6 \mathrm{dBm}$

The total power consumption for the three modules is only $4.6 \mathrm{~W}$. The preamplifier module is designed to increase the minimum input power for HPA. By using this approach, the HPA design requires the only $4.25 \mathrm{~W}$, with using $5 \mathrm{~V}$ and 850 $\mathrm{mA}$ power supply. This solution meets the power budget of satellite system constraint, which only allows less than $5 \mathrm{~W}$ power consumption. Fig. 2 shows the developed qualification model of the adaptive transmitter. The HPA grounding is designed to have a direct connection to the aluminium casing, as part of the transmitter heat circulation. The transmitter is capable of transmitting for the complete duration of satellite contact with the ground station using the proposed technique.
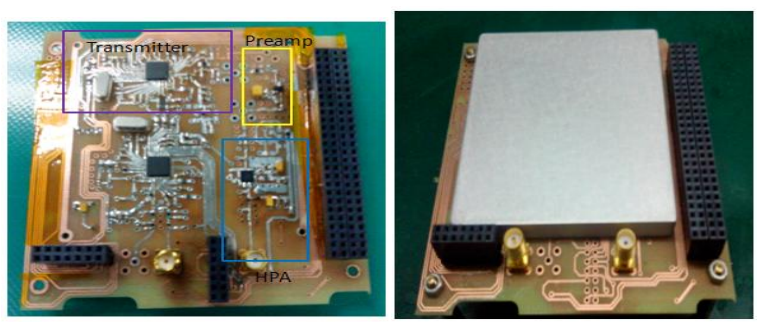

Fig. 2.Qualification Model (QM)

The subsystem involves with the adaptive transmitter are OBC and Power System. The satellite trajectory information is stored and managed by the OBC. The OBC also manages the satellite operations and task schedule that trigger when the transmitter need to turn ON or OFF. Transmitter with adaptive function only requires one additional input from OBC for elevation angle data and provide selection output for the data rate and RF transmit power to transmitter front end. The configuration model of the adaptive transmitter is determined by the ATCU [13]. Fig. 3 shows the block diagram of the adaptive transmitter.

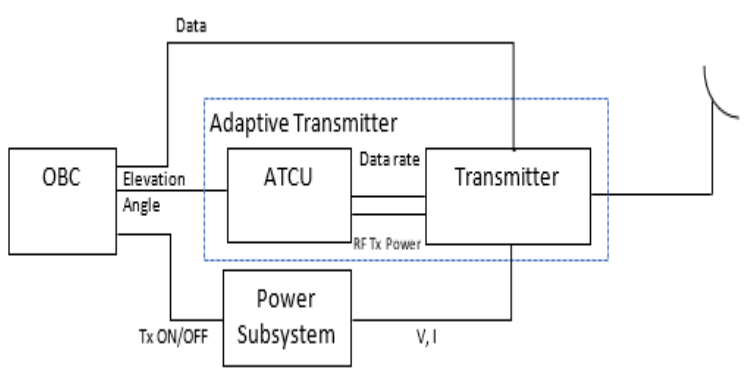

Fig. 3.Block Diagram of the Adaptive Transmitter.

\section{B. Thermal Vacuum Chamber Test}

The adaptive transmitter is the Device Under Test (DUT); it is assembled inside the CubeSat structure with other subsystems, such as the OBC and power module, as shown in Fig. 4. The functional test measurement is performed in a laboratory environment to benchmark its specifications. The equipment in this test is a spectrum analyser with a counter function and power measurement. As shown in Fig. 5, the TVAC test setup was conducted in the environmental laboratory. The $30-\mathrm{dB}$ attenuator is placed between the transmitter and the spectrum analyser for safety purposes. The cable loss and 20-dB attenuator are measured before assembly with a DUT setup. The measured loss is $28 \mathrm{~dB}$, which will be deducted from the power reading to obtain an exact reading.
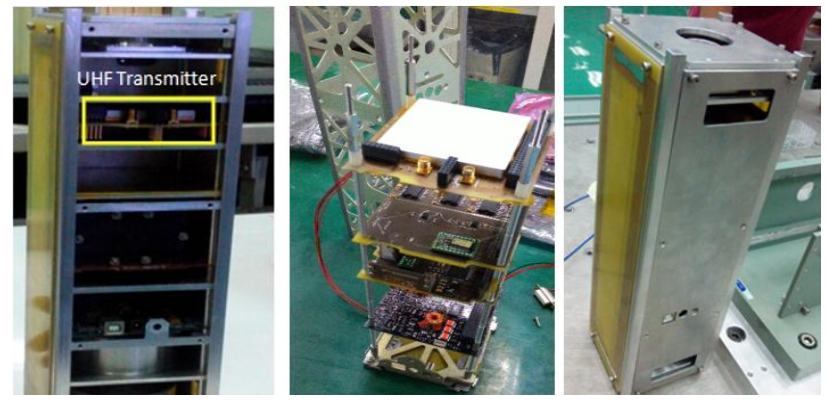

Fig. 4.Adaptive Transmitter integrated into CubeSat.

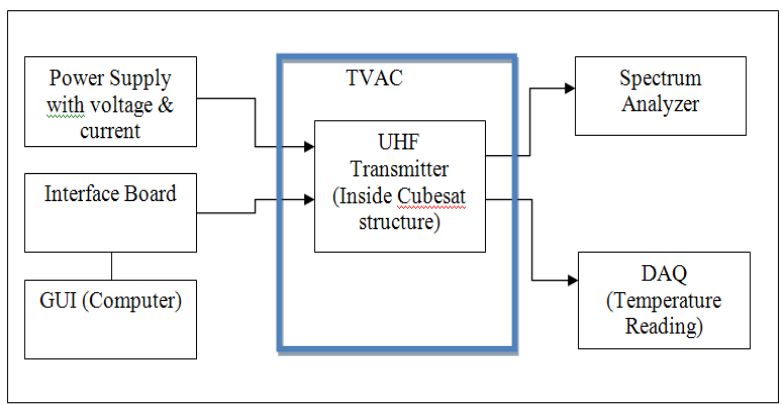

Fig. 5.TVAC Test Setup Configuration.

The facility in this test is the vacuum thermal shock equipment at the Kyushu Institute of Technology (KIT) Center for Nanosatellite Testing (CeNT) at the Laboratory of Spacecraft Environment Interaction Engineering, Japan. Liquid nitrogen is used to cool the shroud around CubeSat to create a low-temperature environment [18]. Fig. 6 shows the TVAC monitoring station, which is used to control the chamber temperature, configure the transmitter and record the results. For high-temperature conditions, the heaters are attached to the CubeSat structure, which created mild conditions. The temperature control is performed using the average value of the temperatures of five points on the CubeSat structure near the mounting screws. The thermal profile is set in advance, and the reading is available at the monitoring GUI. The electrical interface for power, telemetry and command, as well as the RF signals are established using cables through a D-sub connector at the chamber wall. 

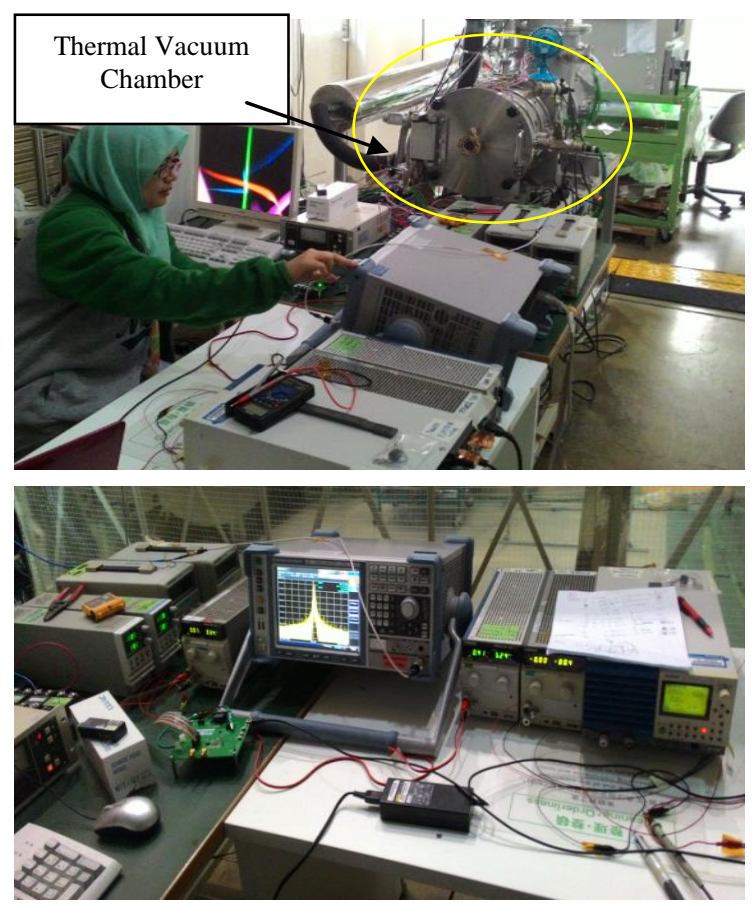

Fig. 6.TVAC Monitoring Station.

The test condition for the thermal vacuum cycling test is presented at Table III, where the chamber temperature started at $+20^{\circ} \mathrm{C}$ (room temperature) and then decreased to $-20^{\circ} \mathrm{C}$ [19]. The transmitter is switched ON for 15 minutes and turned OFF for 2 minutes. The transmitter is turned ON for 15 minutes, which is determined by the estimation of the maximum satellite contact time per pass. No reading is collected when the transmitter is turned off. The temperature is then increased to $+60^{\circ} \mathrm{C}$ and maintained for 1 hour. After the dwell stage, the temperature is reduced to $-20^{\circ} \mathrm{C}$ to complete one thermal vacuum cycle. The TVAC temperature profile is set as shown in Fig. 7. The CubeSat is assembled in the TVAC, as shown in Fig. 8.

Table- III: Test condition for the Thermal Vacuum Cycling Test

\begin{tabular}{|l|l|}
\hline Item & Value \\
\hline Start temperature & $+24^{\circ} \mathrm{C}$ \\
\hline Temperature cycle & 4 \\
\hline High temperature & $+60^{\circ} \mathrm{C} \pm 2^{\circ} \mathrm{C}$ \\
\hline Low temperature & $-20^{\circ} \mathrm{C} \pm 2^{\circ} \mathrm{C}$ \\
\hline $\begin{array}{l}\text { Dwell time @ extreme } \\
\text { temperature }\end{array}$ & 1 hour \\
\hline Temperature ramp rate & $\pm<1^{\circ} \mathrm{C} /$ min \\
\hline Vacuum pressure & $10^{-3} \mathrm{~Pa}$ or better \\
\hline
\end{tabular}

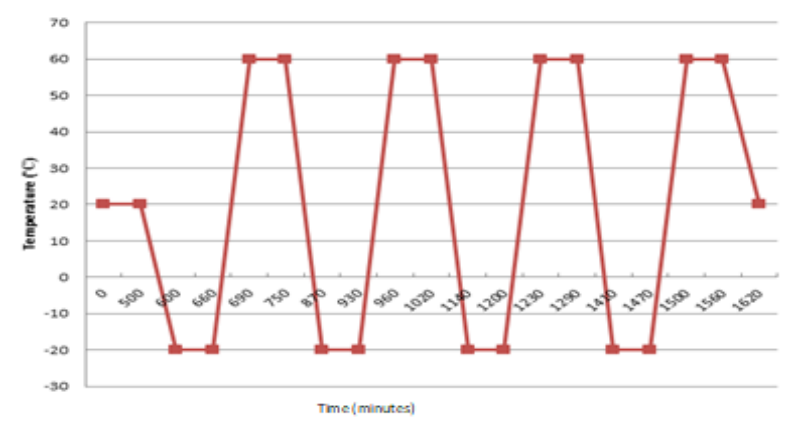

For temperature monitoring, nine thermal couples are employed; five of the couples are located at each axis of the CubeSat structure and every subsystem. Fig. 9 shows the temperature reading for the nine thermal sensors attached inside the TVAC. The thermal sensor located at the transmitter is designated as TC COMM, as shown in Fig. 9. Only TC COMM reading is taken as the adaptive transmitter temperature while other sensors are used by other satellite subsystem monitoring such as $\mathrm{OBC}$, power module and satellite thermal analysis.

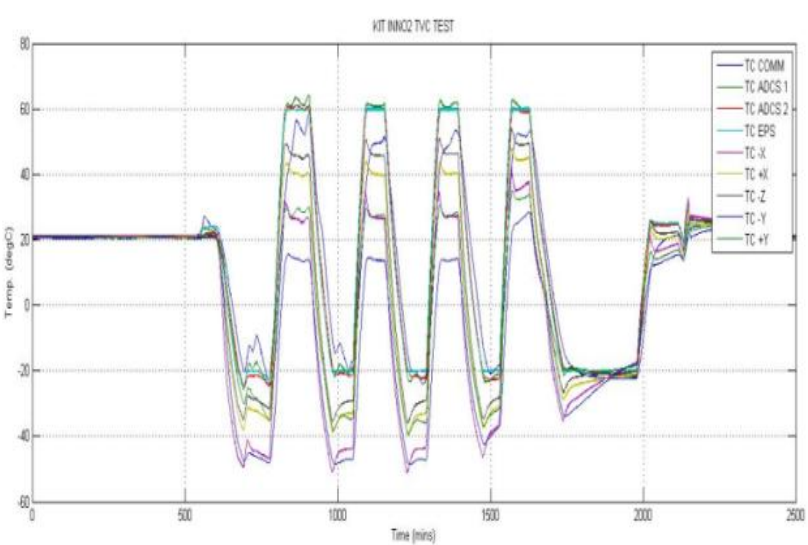

Fig. 9.Temperature reading inside the chamber.

\section{RESULT AND DISCUSSION}

The transmitter is turned ON before and after the chamber is closed to ensure that everything is in good condition before the vacuum process starts. Six hours are required to vacuum the chamber thoroughly. The TVAC test result summary is listed in Table IV. Fig. 10 shows the spectrum analyser output of the DUT. From this measurement, the RF power reading is $+2.5 \mathrm{dBm}$ after deducting the losses and attenuator, with an equivalent value of $28 \mathrm{~dB}$. Therefore, the result is $+30.5 \mathrm{dBm}$. Measurements are taken when the adaptive power control function is configured at $1 \mathrm{~W}$ or $+30 \mathrm{dBm}$. 


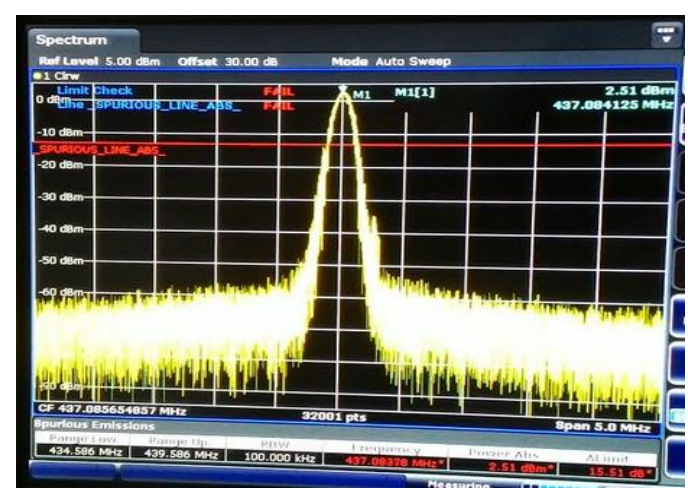

Fig. 10.Frequency and Power Measurement Result.

Table- IV: TVAC Test Results

\begin{tabular}{|l|l|l|l|}
\hline \multicolumn{1}{|c|}{ Test Item } & Requirement & Performance & Compliance \\
\hline $\begin{array}{l}\text { Frequency } \\
\text { (MHz) }\end{array}$ & $\begin{array}{l}437.084 \\
\text { (UHF band) }\end{array}$ & 437.084 & $\begin{array}{l}\text { Fully } \\
\text { complied }\end{array}$ \\
\hline Transmit & $27 \mathrm{dBm}$ & $27.4 \mathrm{dBm}$ & Fully \\
Output & $30 \mathrm{dBm}$ & $30.5 \mathrm{dBm}$ & complied \\
Power & $31.8 \mathrm{dBm}$ & $32.0 \mathrm{dBm}$ & \\
& $33 \mathrm{dBm}$ & $32.8 \mathrm{dBm}$ & \\
& \multicolumn{3}{|l}{} \\
\hline
\end{tabular}

The RF output power and the temperature reading during the thermal vacuum test are plotted in Fig. 11. Throughout the four cycles test, the RF output power is consistent at +33.0 $\mathrm{dBm}$ with less than $\pm 5 \%$ tolerance, except two conditions, which are during the dwell transition at $-20^{\circ} \mathrm{C}$, as shown by the yellow circle in Fig. 11. These findings indicate that there is the possibility of slightly power reduction during negative temperature and further test with eight temperature cycles in the thermal chamber will be conducted. Based on the overall measurement, results indicate that the transmitter is stable at high temperatures compared to low temperatures. The transmitter capable of maintaining the output power within the temperature range proves that the transmitter heat circulation is functioned. The transmitter temperature reading is measured at the aluminium casing, which is part of the transmitter heat circulation. From the measured temperature, the HPA temperature is within a stable range even though the transmission is conducted continuously. The standalone HPA module without heat circulation is only capable of having continuous transmission of not more than 15 minutes.

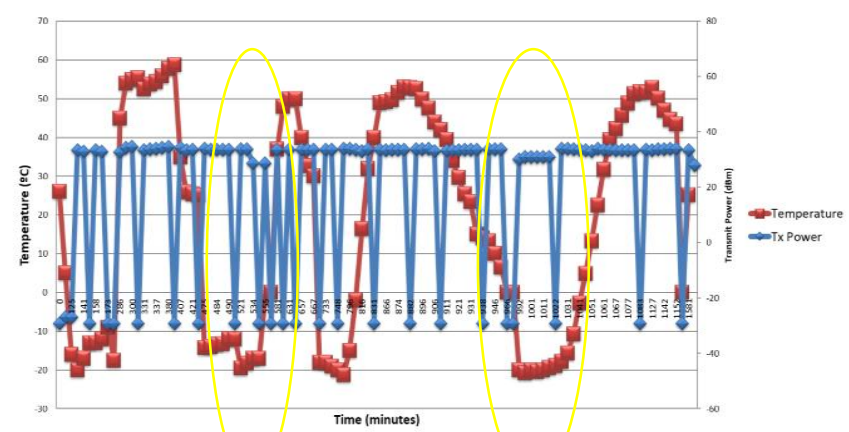

Fig. 11.RF Transmiit Power and temperature of the TVAC test.

In order to monitor the frequency synthesiser stability, the RF frequency output and temperature reading during the thermal vacuum test are measured and plotted in Fig. 12. Based on the thermal vacuum test activity, the transmitter has fully complied with the stability requirement, which is less than 2 ppm tolerance for a wide operating temperature range [20].

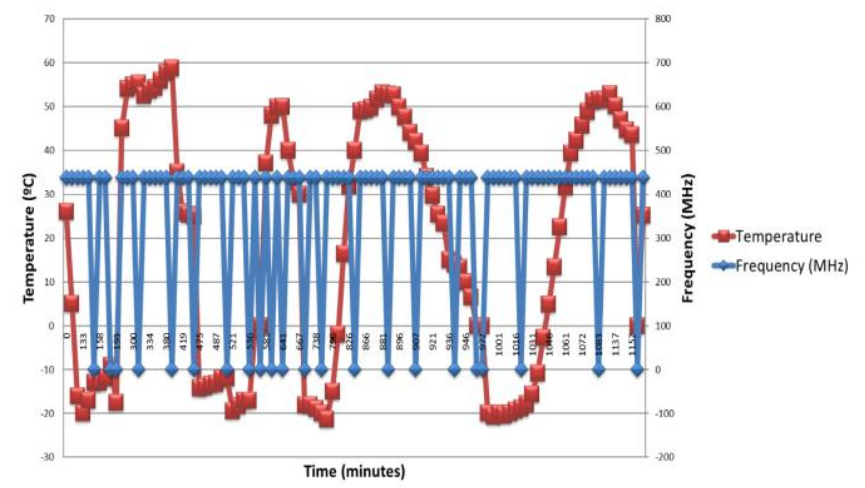

Fig. 12.RF Frequency Output and temperature of the TVAC test.

The adaptive function is tested for four cycles, but the frequency of measurement is reduced to only two or three readings at each temperature transition. The transmitter is configured to transmit at five different outputs, as shown in Fig. 13. Based on the plotted output, the power control function can transmit at different output power levels throughout the TVAC temperature test. Two readings are obtained, which indicates that the output is slightly lower at a temperature of $-20^{\circ} \mathrm{C}$. The low output power is possible due to the operating temperature limit for some of the components used in the design.

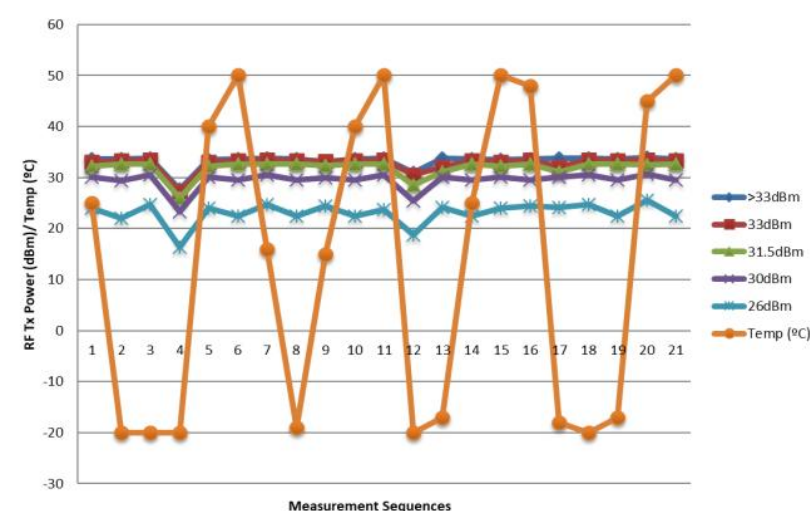

Fig. 13.RF Transmit Output using Power Control Function.

Based on the results analysis, the developed transmitter capable of reconfiguring the RF output powers within the wide range of temperature and this verified that the adaptive transmitter is performed according to the required specification in the thermal vacuum condition. The RF transmit power and frequency measurement results ensure that the developed transmitter is capable of continuing transmitting for the full duration of typical satellite pass duration. At the same time, these finding verified the thermal heat circulation is properly designed and achieved the satellite mission requirements. 


\section{CONCLUSION}

The UHF transmitter with an adaptive control function is designed and developed in this research. This paper focuses on the design, the validation methodology in the thermal vacuum, the analysis of measured output based on the adaptive function and the accuracy of the transmission frequency. The transmitter is developed using industrial-grade components and fully complies with the RF output power and frequency stability requirements. The ATCU model is also tested and demonstrated to be working in the thermal vacuum test. The results indicate that the adaptive transmitter can perform as per CubeSat requirements in the thermal vacuum condition. This outcome validates that the adaptive transmitter is suitable for CubeSat application and has the potential to improve the SNR and power consumption, by adopting the ATCU model. The adaptive function of this transmitter will be the design foundation for the future type of CubeSat transmitter with an adaptive transmitter control unit that operates in various frequency bands.

\section{ACKNOWLEDGMENT}

F. D. Jaswar would like to thank the mentor of this project, Prof. Tharek Abd. Rahman and the following person, institution, and companies that help by giving advice, by supporting the project and providing hardware and software, colleagues from Astronautic Technology (M) Sdn Bhd (ATSB), Wireless Communication Center at Universiti Teknologi Malaysia, the Kulliyah of Engineering, International Islamic University and Kyushu Institute of Technology Center for Nanosatellite Testing (CeNT), Laboratory of Spacecraft Environment Interaction Engineering.

\section{REFERENCES}

1. B. Klofas and J. Anderson, "A Survey of CubeSat Communication Systems," Micro, no. September 2012, pp. 1-25, 2013.

2. O. Popescu, J. S. Harris, and D. C. Popescu, "Designing the communication sub-system for nanosatellite CubeSat missions: Operational and implementation perspectives," Conf. Proc. - IEEE SOUTHEASTCON, vol. 2016-July, 2016.

3. J. R. Wertz and W. J. Larson, Space mission analysis and design. Kluwer Academic, 1991.

4. S. C. Ekpo and D. George, "A system engineering analysis of highly adaptive small satellites,” IEEE Syst. J., vol. 7, no. 4, pp. 642-648, Dec. 2013.

5. O. Popescu, "Power Budgets for CubeSat Radios to Support Ground Communications and Inter-Satellite Links," IEEE Access, vol. 5, pp. 12618-12625, 2017.

6. E. Grayver, A. Chin, J. Hsu, D. Kun, and A. Parower, "Software Defined Radio for Small Satellites," IEEE, no. 978-1-4799-5380-6/15, pp. 1-9, 2015.

7. M. Héder, "From NASA to EU: The evolution of the TRL scale in Public Sector Innovation," Innov. J., vol. 22, no. 2, pp. 1-23, 2017.

8. H. Fujii, T. Asai, and Y. Okumura, "Capacity Achievable by Spectrum Sharing with Adaptive Transmit Power Control: Based on Field Measurements," October, 2009.

9. S. Negrón, J. I. Reyes, J. M. Limery, and C. Design, "Smart Power Supply Unit for a Cubesat," 2011.

10. S. C. Ekpo, "Receiver G / T Ratio Improvement for Space Communications Missions," pp. 1-3, 2011.

11. J. Friedel and S. McKibbon, "Thermal Analysis of the CubeSat CP3 Satellite," Aerosp. Eng., no. March, p. 22, 2011.

12. ECSS-Q-ST-70-02C, "Space product assurance: Thermal vacuum outgassing test for the screening of space materials," no. November, pp. $1-45,2008$.

13. F. D. Jaswar, T. A. Rahman, M. N. Hindia, and Y. A. Ahmad, "Design of an adaptive CubeSat transmitter for achieving optimum signal-to-noise ratio (SNR)," IOP Conf. Ser. Mater. Sci. Eng., vol. 270, no. $1,2017$.

14. NASA, "Small Spacecraft Technology State of the Art," no. 1 Dec, pp. 1-197, 2015.

15. J. Castellví, A. Camps, J. Corbera, and R. Alamús, "3Cat-3/MOTS nanosatellite mission for optical multispectral and GNSS-R earth observation: Concept and analysis," Sensors (Switzerland), vol. 18, no. $1,2018$.

16. California Polytechnic State University, "6U CubeSat Design Specification Rev . PROVISIONAL," CubeSat Progr., no. Rev. Provisional, p. 26, 2015.

17. T. Choi, T. Stevenson, and E. G. Lightsey, "Reference Ground Station Design for University Satellite Missions with Varying Communication Requirements," 55th AIAA Aerosp. Sci. Meet., no. January 2017, pp. 1-8, 2017.

18. M. Cho, H. Masui, T. Hatamura, K. Date, H. Shigekatsu, and O. Shoichi, "Overview of Nano-satellite Environmental Tests Standardization Project: Test Campaign and Standard Draft," 26th Annu. AIAA/USU Conf. Small Satell., p. 11, 2012.

19. D. Nasa et al., "Dellingr: NASA Goddard Space Flight Center's First 6U Spacecarft," 31st Annu. AIAA/USU Conf. Small Satell., 2017.

20. NASA-CCSDS, "CCSDS Radio Frequency and Modulation systemspart1 Earth stations and space craft," no. Blue Book, Issue 1 \& 2 Recs. 2000 .

\section{AUTHORS PROFILE}

Ir. Fitri Dewi Jaswar was born in Selangor, Malaysia, in 1980. She received the bachelor degree in electrical engineering from the UniversitiTeknologi Malaysia (UTM), Malaysia, in 2001, the M.Sc. in electrical engineering from UTM, Malaysia, in 2007 and continuing $\mathrm{Ph}$. D. at UTM under Wireless Communication Center from 2014.

In 2004, she joined Astronautic Technology (M) SdnBhd (ATSB) as spacecraft engineer and participated in technology transfer program with RazakSAT engineers. RazakSAT is the first satellite launch at Near Equatorial Orbit in the world under Malaysia Satellite program. She has been working with Satellite Engineering Department and was granted with Technofund RMKE-9 under Ministry of Science, Technology, and Innovation (MOSTI) and receipted completion certificate from MOSTI in 2013 for completing development of X-band Transmitter System project. She also involved and completed the development of CubeSAT and InnoSAT communication subsystem.

Prof. Dr. Tharek Abd Rahman is a Professor at Faculty of Electrical Engineering, Universiti Teknologi Malaysia (UTM). He obtained his BSc. in Electrical \& Electronic Engineering from University of Strathclyde UK in 1979, MSc in Communication Engineering from UMIST Manchester UK and $\mathrm{PhD}$ in Mobile Radio Communication Engineering from University of Bristol, UK in 1988. He is the Director of Wireless Communication Centre (WCC), UTM. His research interests are radio propagation, antenna, and RF design and indoors and outdoors wireless communication. He has also conducted various short courses related to mobile and satellite communication to the Telecommunication Industry and Government body since 1990 . He has a teaching experience in the area of mobile radio, wireless communication system and satellite communication. He has published more than 120 papers related to wireless communication in national/international journal and conference.

Ir Yasser Asrul Ahmad joined the International Islamic University Malaysia (IIUM) in 2015. He was an Academic Fellow at the Kulliyyah of Engineering. He obtained his BSc. in Electrical \& Electronic Engineering from Vanderbilt University and MSc in Communication Engineering from Universiti Kebangsaan Malaysia (UKM). His research interests are satellite development and communication system and operation. 